\title{
Study of Kenyan Optometrists View on Future of Optometry and Prospective Impact on Public Health
}

Shadrack Muma ( $\nabla$ mumashadrack275@gmail.com )

Maseno University https://orcid.org/0000-0002-0598-1632

Stephen Obonyo

Strathmore University

Research article

Keywords: view; optometry status; Kenya;concerns; optometrists.

Posted Date: August 25th, 2020

DOI: https://doi.org/10.21203/rs.3.rs-60032/v1

License: (c) (i) This work is licensed under a Creative Commons Attribution 4.0 International License. Read Full License 


\section{Abstract}

Background: VISION 2020: The Right to Sight, was to ensure that by the year 2020, a great reduction in the incidences of avoidable blindness be recorded. This was achivable by training optometrists. Kenya has a population of 47 million, with 56 registered optometrists who are not regulated by the government. However there is no data on optometrists view on the future of optometry in Kenya and the public health implication.

Methods: A semi-structured questionnaire was emailed to 56 registered optometrists. The questionnaire contained broad areas such as demographics of participants, their view on status of optometry in kenya, challenges faced by the optometrists, availability of lecturers, their concerns on the way forward and how these issues impacts on public health. A chi-square was used to look at associations and odds ratio was computed.

Results: A vast majority (90\%) of the respondents suggested that regulating optometry will be the only solution to their problems. Most respondents $91.7 \%$ agreed that the situation has impacted negatively on the public health. General public awareness on what is optometry should be enhanced $79 \%$. The qualitative analysis produced four broad themes: (1) regulation; (2) unity; (3) public health implication and (4) creating public awareness.

Conclusion: The key recommendations was to lobby for regulation of optometry practise and there is need for public awareness on what is optometry and their role in the eye care. Adequate lecturers should be recruited to ensure quality among graduates in delivery to the public.

\section{Background}

Avoidable blindness has received alot of attention from international organisations, Non Governmental Organisations, different governments and the World Health Organisation. ${ }^{1}$ Coming up with VISION 2020: ${ }^{2}$ The Right to Sight, was to ensure that by the year 2020, a great reduction in the incidences of avoidable blindness be recorded. The intitiative was only achievable if training of optometrists would be given a priority. The VISION 2020 recomended one optometrists for every 50000 population. ${ }^{3}$ To achieve this guideline for Kenya, roughly 950 optometrists are required for the 47 million population. Upto date, Masinde Muliro University, Kenya Medical Training College are the only institutions offering optometry in Kenya. ${ }^{4}$ The Kenya Medical Training College began a Diploma in Optometry in 2006 with approximately 20 optometrists graduating every year. In 2009, Masinde Muliro University started Bachelor of Science in Optometry and Vision Sciences with roughly 20 optometrists graduating every year. This translate that by 2014 kenya was producing 40 optometrists each and every year. In as much as we are in 2020 already, the target required for VISION 2020 has not been achieved. Being that kenyan optometrists are not recognised by the government, it proves hard to ascertain whether the existing optometrists really practices or majority are engaged in other activities rather than optometry. 
Optometrists in United States for instance provide more than two-thirds of the primary eye care. ${ }^{5}$ They are more widely distributed geographically than other eye care providers and are readily accessible for the delivery of eye and vision care services. There are approximately 32,000 full-time equivalent doctors of optometry currently in practice in the United States while in kenya, only 56 optometrists practices legally. Other countries like Nigeria, have produced over 3500 optometrists who are regulated. ${ }^{6}$ In kenya, it is only level six hospitals which provides comprehensive eye care services and they are affiliated to county governments and national government. ${ }^{7}$ Kenya has fourty seven counties with each having a level six facility. All level six hospitals offer ophthalmology services under management of ophthalmologists, ophthalmic clinical officrs and ophthalmic assistants nurses. ${ }^{8}$ All these cadres are exemplary trained to offer cataract surgeries and ocular diseases treatment, however optometrists are not incoporated when uncorrected refractive error is one of the leading causes of avoidable blindness. Kenya has approximately 115 ophthalmologist and 100 ophthalmic clinical officers. ${ }^{9}$ In comparision to other African countries such as South Africa, Nigeria there are more than five training institutions offering optometry. ${ }^{10}$ While ophthalmic clinical officers and ophthalmic nurses are trained to assist ophthalmologists, they also provide optometric services which they are not well conversant with. In relation to emerging issues related to refractive error, ophthalmic clinical officers may find it hard to understand these refractive conditions resulting to innapropriate management. In developed countries like United Kingdom, roles of each and every eye care provider is clearly written down and all the providers only practices within their scope. ${ }^{11}$ This greatly influnces the quality of eye care services.

The existing optometrists in kenya thinks that optometry was introduced without proper plans and they are facing hard times to proclaim their existance. This has been among majority of developing countries such as Nigeria, Ghana where optometry took so long to be recognised untill most graduates gave up. ${ }^{12}$ Getting alot of resistance from other cadres has made optometry appear like a non unique programme not necessary in eye care industry. Optometry in kenya is not regulated and this leaves the optometrists to remain without a say especially in the ophthalmic division. ${ }^{13}$ in United States, optometry is regulated. ${ }^{14}$ Other African countries such as South Africa, Nigeria and Uganda are regulated and have active associations. ${ }^{15}$ The kenyan optometrists came up with an association called Optometrists Association of Kenya to promote the rights of the optometrists. ${ }^{16}$ In January 2020, there were around 56 optometrists registered with the association, with majority working in private sector. However the association does not offer membership exam making it open for anyone who claims to be an optometrits to practice. In Nepal for instance, optometry trianing is accompanied by entrance exams. ${ }^{17}$ Preliminary evidence suggest that optometry in kenya is at stand still, optometrists expriences alot of challenges, the training institutions have insufficient lecturers and concerns of optometrists to move forward is still on course. ${ }^{18}$ However evidence to support these assertions are required. Hence a survey was conducted to understand the optometrists view on the future of optometry, their view on the challenges faced, their view on training, their views on future plans and the public health implication.

\section{Methods}


This was a prospective study in which respondents received the survey through emails. The survey was developed by author SM using a goggle form. The survey was sent to email addresses of 56 optometrists between 20 February and 13 March 2020. After sending one reminder, 39 responses were received. The participants were only registered optometrists. The follow up letter encouraged the non respondents and explained to them the importance of the study again. The response rate was thus $70.2 \%$ (39 out of 56 ). Participation in the survey was voluntary, and the respondents could withdraw from the survey at any time during the study period. The responses were kept confidential, and the data were de-identified before data analysis. The Helsinki Declaration was adhered to. All ethical standards for research without direct contact with human or animal subjects were observed.

The survey included 14 semi-structured questions broadly around respondent's demographic characteristics, status of optometry in kenya, problems faced by optometrists in kenya, availability of lecturers at the 2 training institutions and concerns of optometrists to move foward. The questions had two to five responses. The questionnaire also consisted of two open-ended questions to get the optometrists concerns and way forward for optometry and also the public heath implication. Content of the survey questionnaire was tested on five members for validation. The questionnare yielded a reliability of 0.94 and to test for validity, a Pearson correlation coefficient was used where a sig. (2 tailed) of 0.000 $<0.05, \mathrm{~N}=5$ was obtained. Quantitative and qualitative analysis was performed using Statistical Package for Social Sciences version 17.

\section{Results}

\section{Demographic Characteristics of Respondents}

The mean age and standard deviation of the 39 respondents was $26.4 \pm 4.3$ years ( 25 to 34 years). The respondents had practised for an average of $2.2 \pm 5.3$ years (range 1-10 years) after their optometry aschool graduation. Majority $94.7 \%$ of the participants were living in Kenya. There was an association between the number of years after graduation and country of residence of the respondents (t-test, $p=$ 0.26). based on level of education, $64 \%$ had a diploma, $32 \%$ had a bachelor and $4 \%$ had earned master degree. Majority of the respondents had graduated from Masinde Muliro University. Most respondents were working in private sectors $78.9 \%, 15.8 \%$ in public sector and $5.3 \%$ were not practising optometry.

\section{Demographic characteristics of survey respondents.}

The optometrists with a diploma were 3.27 (95\% confidence interval [Cl] 0.68-4.94) times likely to remain in Kenya compared to those with a bachelor qualification $(p=0.04)$. The highest degree of qualification was not significantly different between optometrists graduates from Masinde Muliro University and those from Kenya Medical Training College $(x 2=4.30, p=0.02)$. Kenya Medical Training College graduates were 0.24 (95\% $\mathrm{Cl} 0.17-0.72)$ times likely to remain in Kenya compared to those graduates from Masinde Muliro University $(p=0.02)$. (Table 1.0) 
Table 1.0

Demographic characteristics

\begin{tabular}{|ll|}
\hline Female $\{\mathrm{n}(\%)\}$ & $10(26.3 \%)$ \\
\hline Male $\{\mathrm{n}(\%)\}$ & $29(73.7 \%)$ \\
\hline $25-29$ years $\{\mathrm{n}(\%)\}$ & $12(31.6 \%)$ \\
\hline $30-34$ years $\{\mathrm{n}(\%)\}$ & $17(68.4 \%)$ \\
\hline $1-5$ years practice $\{\mathrm{n}(\%)\}$ & $27(68.4 \%)$ \\
\hline $6-10$ years practice $\{\mathrm{n}(\%)\}$ & $12(31.6 \%)$ \\
\hline Reside in Kenya $\{\mathrm{n}(\%)\}$ & $37(94.7 \%)$ \\
\hline Reside outside $\{\mathrm{n}(\%)\}$ & $2(5.3 \%)$ \\
\hline Diploma $\{\mathrm{n}(\%)\}$ & $19(47.4 \%)$ \\
\hline Bachelor $\{\mathrm{n}(\%)\}$ & $12(31.6 \%)$ \\
\hline Masters $\{\mathrm{n}(\%)\}$ & $8(21.1 \%)$ \\
\hline Graduated from KMTC $\{\mathrm{n}(\%)\}$ & $19(47.4 \%)$ \\
\hline Graduated from MMUST $\{\mathrm{n}(\%)\}$ & $20(52.6 \%)$ \\
\hline Working in private sector $\{\mathrm{n}(\%)\}$ & $31(78.9 \%)$ \\
\hline Working in public sector $\{\mathrm{n}(\%)\}$ & $6(15.8 \%)$ \\
\hline Working in other sector $\{\mathrm{n}(\%)\}$ & $2(5.3 \%)$ \\
\hline
\end{tabular}

\section{Summary of the optometrists survey findings.}

\section{Optometrists Resistance By Other Cadres}

Over a third (52.6\%) of the respondents agreed that optometry in kenya still has a long way to be regulated. Based on resistance from other cadres, $57.9 \%$ of the respondents agreed that optometrists will continue to receive resistance from other cadres if regulation has not been achieved. Awareness on optometry is still an issue and $78.9 \%$ agreed that the general population are still not aware of what is optometry. More than half (63.2\%) of the respondents agreed that employers take advantage of optometrists frustrations in kenya. On salary basis, $52.6 \%$ of the respondents agreed that they are poorly paid. Lastly on the basis of faculty staffs, $68.4 \%$ agreed that optometry teaching institutions have insufficient lecturers and they suggested that graduates from the instututions should be considered to mentor the upcoming optometrists. The situation of optometrists has impacted on the public health and the optometrists were $2.32(95 \% \mathrm{Cl} 0.27-0.42)$ times ikely to deliver poor services to the public compared to if optometry situation was better in kenya. 


\section{Concerns From Optometrists}

Thematic analysis resulted into four broad themes: (1) regulation; (2) unity; (3) public health implication and (4) creating public awareness, which consisted of a total of 124 comments. (Table 2.0)

Table 2.0

Major themes on future of optometry

\begin{tabular}{|lll|}
\hline $\begin{array}{l}\text { Theme } \\
\text { number }\end{array}$ & Major themes & Number of coded segments \\
\hline Theme 1 & There is need for optometry regulation in Kenya & 47 \\
\hline Theme 2 & Optometrists need to remain united & 34 \\
\hline Theme 3 & $\begin{array}{l}\text { Need for awareness campaign on what is } \\
\text { optometry }\end{array}$ & 31 \\
Theme 4 & Public health implication & 17 \\
\hline
\end{tabular}

\section{Regulation}

About $90 \%$ of the respondents expressed concerns about regulation of optometry in kenya. Majority of them said that for optometry to move forward, there is need for regulation and inclusion into the public service:

'How can we optometrists demand for a better working conditions when we are not regulated?' (Participant ID23, male)

Many of them were questioning why optometry was introduced in a government institutions when there was no proper plan for the graduates. Many participants said that a scheme of service should be established to incoporate optometrists into public service. Some participants reported that they face it hard to engage the ophthalmic division because the division through members feel insecure on the existance of optometrists. Majority suggested that the executive for the association should engage the ophthalmic division with well articulated documents to support why they should include optometrists into ophthalmic division.

\section{Unity}

Nearly all respondents $86 \%$ expressed concerns regarding unity among the graduates from both institutions. Majority suggested that all graduates should treat each other as equal regardless of the institution of graduation.

'How can we claim to be united when optometrists from one institution look down upon their collegues from the other institution?' (Participant ID33, female) 
They highlighted the need to be united and fight for their rights under one united pool.

\section{Public Health Implication}

About three quarter of the respondents $91.7 \%$ were highly concerned on how the frustration make them not deliver best to the public. Generally the core reason for public health is to ensure that the general population obtain preventive measures for the population. Now in the kenyan context, the frustrations faced by the optometrists has impacted negatively on the delivery of eye care services.

'As optometrists, it is our role to provide eye care services to the general public based on our scope of training but the status of optometry in kenya has made the worse by making the public our enemy.' (Participant ID12, male)

\section{Creating Public Awareness}

Nearly three quarter $79 \%$ of the respondents agreed that optometry is still unknown. 'Where i work i have to introduce myself as an optician because when a patient ask me who am $\mathrm{i}$ and $\mathrm{i}$ say optometrist then they will say, why do you complicate yourself, you are an optician?' (Participant ID09, male). The respondents identified this as a major challenge and they highlighted the need to create public awareness about optometry and who are optometrists.

\section{Discussion}

The results of the survey has provided a comprehensive view of Kenyan optometrists about future of optometry in Kenya. Kenya needs optometrists because the growing population will need access to eye care services. The optometrists were highly concerned about regulation of optometry and unity among the optometrists. In comparision to other African countries like Nigeria, regulation took soo long but finally the graduates got recognition. ${ }^{19}$ Therefore, the current situation is not only among Kenyan optometrists but majority of countries in Africa still find optometry unique and not relevant.

One hundred percent of the optometrists were working in Kenya and this is comparable to nutrition graduates who are highly stationed in kenya after graduation. ${ }^{20}$ in Nepal, this is the contrary, where majority of graduates are moving outside Nepal to look for better work places in other countries. ${ }^{21} \mathrm{~A}$ study by Kandel et al showed that almost half of the graduates were not working in Nepal. ${ }^{22}$ The retention rate in Kenya is greatly higher in comparision to ophthalmologists $15 \%$ retained in Kenya with over $45 \%$ working in other countries or doing other things. ${ }^{13}$ This study found that optometrists graduates from the two institutions in kenya are 3.27 times more likely to remain in Kenya than moving to other countries. The high rate of retention is posible because of three reasons: first the graduates are not licenced hence they find it hard to be accepted in other countries, secondly the training does not give entrance examination hence fear from graduates that they may be subjected to exams if they travel to other countries and finally, the quality of graduates is less competitive hence they are contented in kenya. A study conducted in Uganda showed that optometrists can diagnose and manage about $75 \%$ of eye 
condition in patients presenting in the primary health care centre with $100 \%$ management of refractive error. ${ }^{23}$ Data on this is not available in kenya, however in relation to the training given to kenyan optometrists, a similar proportion could be the case. Hence the government should extend a hand of recognition of optometrists as primary eye care providers in the country as it is the case in Uganda.

To ensure uniformity on optometry training, there is need for curriculum to be evaluated. For instance Masinde Muliro University in 2009 introduced a bachelor of science in optometry and vision sciences which was a four year programme. However as at now the programme has changed to bachelor of optometry which is a five year programme. ${ }^{24}$ The Kenya Medical Training College which offers a three year diploma optometry has maintained. In developed countries such as United States, training of optometrists is uniform and the curriculum has been made at one level. ${ }^{25}$ This makes the quality of graduates to go higher and maintained universally. Therefore the participants suggestions were to ensure that the three year diploma graduates to be accepted to enroll for a bachelor of optometry. This will ensure that the scope of practice is uniform.

More than two-thirds of the respondents agreed tha Masinde Muliro University had enough equipment, however the practical training has not achieved a threshold in the sense that the students are only exposed to these equipment at the final year. It is argued that learning by doing practicals increase the success rate of students as it is evident in other programmes like engineering. ${ }^{26}$ At the same time staffing should be adequate to ensure quality training. An exchange training programme should exist between students from the two institutions. The situation as it is in kenya has negatively impacted on the public health. The optometrists are not motivated and as a result they do not deliver best to the public.

Studies in developed countries such as Britain argue that adequate staffing is important as it motivate students in learning activities. ${ }^{27}$ However this is a major challenge in Kenya since graduates from the two institutions who have made steps to advance to master level and even doctrate level are not given opportunity. This is a major drawback that if not looked at by the instututions then the quaity of the graduates will be low. Hence the optometrists suggeted that faculty staffing be increased and students be allowed to access the practical areas as from second year of study.

In countries such as United States, optometry is well known. ${ }^{28}$ However in the kenyan context, the general public does not know who an optometrists is and what is optometry. Therefore, nearly two third of the optometrists suggested that ther should be a public awareness compaign on who one should see incase they have trouble with their vision. This approach will distinct optometry and be widely known to the general population. Of all the participants, they agreed that unity has been a challenge amongst the optometrists. This has impacted on their potential to move forward as a team. Hence the participants agreed that they need to work in harmony and be strongly united to enable success. In Uganda, unity among optometrists has enabled them to be regulated. In the analysis of 17 documents in countries with optometry, the kenyan scenario applies to two third of the countries. ${ }^{29}$ This shows that not only kenya faces the challenges, but it is a developing countries problem. 
This study had certain strengths: first, quantitative data analysis and qualitative data analysis were performed to explore the view of the optometrists about the situation of optometry in kenya.

Demographic characteristics were analysed with quantitative methods, views of optometrits on the future of optometry were analysed using thematic analysis. Secondly, the response rate of the survey was $71.2 \%$, which is good in relation to a online surveys. Overally online surveys do have low response rates. For example, a meta-analysis of 60 online surveys found a mean response rate of $36 \%$, while the lowest response rate was only $24 \%{ }^{30}$

This study has some limitations: firstly, there are more than 300 optometrists in kenya although only 56 are registered with Optometrists Association of Kenya. The sample size would have been larger if the author would have sent the survey to all optometrists, however being that they are not interested in joining the association for reasons best known to them, accessing their email addresses proved futile. Secondly, as the respondents were only optometrists, the views of the ophthalmic division was not included in the study. Getting the opinion of stakeholders would have better the study. Future studies to be conducted should include the ophthalmic division, ophthalmologists and other regulated eye care providers in kenya to confirm the study findings.

The author compared the study findings with other health professions regarding the regulation and response rate as there was limited published literature on the optometry profession. ${ }^{21}$ However, the author ascertain that this study presented issues that require alot of attention to get optometry regulated in other developing countries. Well optometry is a new profession in many developing countries, this may be a reference document to the ophthalmic divisions and policy-makers inclined towards emerging optometry schools and optometrists regulation.

\section{Conclusion}

Training of optometrists in kenya is very significant as it will reduce the optometrist to population ratio; however, regulation and unity created a concern among existing optometrists. Alot of attention needs to be directed towards regulation, unity, creating public awareness on what is optometry and increasing the number of optometry faculty staffs to ensure quality. Therefore, ophthalmic division should guide the graduates on what they need to do so as to get optometry incoporated into the division since this situation impacts negatively on public health. The findings of this study denotes the significant approaches to be applied and approaches the optometrists should adopt to ressusitate the future of optometry in kenya.

\section{Declarations}

\section{Ethics approval}

Ethical approval was obtained from the institution review board of Maseno University and authority to conduct the study from Ministry of Health. Participation was voluntary, and the respondents could 
withdraw from the survey at any time during the study period. The responses were kept confidential, and the data were de-identified before data analysis. Written consent was emailed to the respondents and after agreeing and signing they sent the written consent back through email to the investigator. The study adhered to the tenets of the Declaration of Helsinki.

\section{Consent for publication}

Not applicable.

\section{Availability of data and materials}

The dataset for the optometrists generated and analyzed during the current study are available from the corresponding author upon reasonable request.

\section{Competing interests}

SM declares that they have no competing interest related to this study.

\section{Funding}

This research did not receive any funding.

\section{Author's contributions}

SM initiated the research concept, developed the proposal, did the data collection and wrote the manuscript. SO improved the research concept assisted with proposal development and reviewed the proposal, analyzed data and the manuscript. All authors contributed equally to the research work. The study was approved by all authors.

\section{Acknowledgement}

We wish to thank all the optometrists who participated in this study and the research assistants.

\section{References}

1. Handley N. Some milestones on the road to scientific refraction. Treasury of Optics (Optisches Museum Jena 90th Anniversary Publication). Ernst-Abbe-Stiftung: Jena; 2012.

2. Khadka J, McAlinden C, Pesudovs K. Quality assessment of ophthalmic questionnaires: review and recommendations. Optom Vis Sci. 2013;90:720-44.

3. Efron N, Brennan NA. Citation analysis of Australia trained optometrists. Clin Exp Optom. 2011;94:600-5.

4. Kim DY. Effects of physics on development of optometry in the United States from the late 19th to the mid 20th century. Korean J Med H. 2014;23:343-71. 
5. Gregg JR. History of the American Academy of Optometry. Washington: American Academy of Optometry; 1987.

6. Suttle CM, Jalbert I, Alnahedh T. Examining the evidence base used by optometrists in Australia and New Zealand. Clin Exp Optom. 2012;95:28-36.

7. Lynch M, Cole P. The College of Optometrists - A History 1980-1998. London: The College of Optometrists; 1999.

8. Mitchell M. A History of the British Optical Association 1895-1978. London: BOA; 1978.

9. Super S. Optometric insights - inaugural lecture, department of optometry Rand Afrikaans University. S Afr Optom. 1984;43:235-49.

10. Davis FO. History of the New Zealand Optometrical Association (Incorporated) 1930-1980. New Zealand Optom Assn Inc.: NaeNae, 1980.

11. DiCola M. Look back - the history of optometry in Canada. Can J Optom. 1998;60:92-8.

12. Kandel H, Murthy GVS, Bascaran C. Human resources for refraction services in Central Nepal. Clin Exp Optom. 2015;98(4):335-41. https://doi.org/10.1111/cxo.12286.

13. World Health Organization. The impact of myopia and high myopia [homepage on the Internet]. Geneva; 2017 [cited 2018 Mar 11]. Available from: http://www.who.int/blindness/causes/MyopiaReportforWeb.pdf.

14. Grit F. Optometry in the Netherlands: the past, the present and the future. Optometry Today 2001; 41 : Issue 3, 9th February.

15. Oduntan OA, Mashige KP, Kio FE, Boadi-Kusi SB. Optometric education in Africa: historical perspectives and challenges. Optom Vis Sci. 2014;91:359-65.

16. Goss DA. Landmarks in the history of Optometry. Hindsight. 2007;38:47-54.

17. Ryan GW, Bernard HR. Techniques to identify themes. Field Methods. 2003;15:85-109.

18. Fereday J, Muir-Cochrane E. Demonstrating rigor using thematic analysis: a hybrid approach of inductive and deductive coding and theme development. Int J Qual Meth. 2006;5:80-92.

19. Schein OD, Vitale S, Cassard SD, Steinberg EP. Patient outcomes of refractive surgery. The refractive status and vision profile. J Cataract Refract Surg. 2001;27:665-73.

20. Bennett AG. An historical review of optometric principles and techniques. Ophthalmic Physiol Opt. 1986;6:3-21.

21. Pesudovs K. Item banking: a generational change in patient-reported outcome measurement. Optom Vis Sci. 2010;87:285-93.

22. Vaughn W, Maples WC, Hoenes R. The association between vision quality of life and academics as measured by the College of Optometrists in Vision Development Quality of Life Questionnaire. Optometry.2006: 77: 116-123.

23. Tengtrisorn S, Sangsupawanitch P, Chansawang W. Cost Effectiveness Analysis of a Visual Screening Program for Primary School Children in Thailand. J Med Assoc Thai. 2009;92(8):1050-6. 
24. Pararajasegaram R. Vision. The right to sight: from strategies to action. Am J Ophthalmol. 2020;1999:128: 359-60.

25. El-Bayoumy M, Saad A, Choudhury AH. Prevalence of refractive error and low vision among schoolchildren in Cairo. Eastern Mediterranean Health Journal. 2007;13:575-9.

26. Khalaj M, Gasemi M, Zeidi I. Prevalence of refractive errors in primary school children [7-15 years] of Qazvin City. Eur J Sci Res. 2009;28:174-85.

27. Kawuma M, Mayeku R. A survey of the prevalence of refractive errors among children in lower primary schools in Kampala district. Afr Health Sci August. 2002;2:69-72.

28. Brien AH, Sylvia S, Kylie K. The challenges of providing spectacles in the developing world. Comm Eye Health J. 2002;13:9-10.

29. Castanon Holguin AM, Congdon N, Patel N, et al. Factors associated with spectacle-wear compliance in school-aged Mexican children. Invest Ophthalmol Vis Sci. 2009;47:925-8.

30. Dandona R, Dandona L. Refractive error blindness. Bull World Health Organ. 2001;79:237-43.

\section{Supplementary Files}

This is a list of supplementary files associated with this preprint. Click to download.

- Questionnaires.docx 